\title{
Evaluation of the Heilongjiang Province Sports Teaching in University Sustainable Innovation Ability Based on GEM-AHP- Fuzzy Evaluation
}

\author{
Shouzhong Zhang \\ zhangshouzhong03@163.com \\ (Harbin Engineering University, Harbin Heilongjiang 150001)
}

\begin{abstract}
The strong or the weak of university sports teaching sustainable innovation ability directly relation to the development of national sports, and affect the national competition strength and international status in the international sports competition.Through analyses the influential factors of the university sports teaching sustainable innovation ability, build up university sports teaching sustainable innovation ability of evaluation primary index; Using the GEM to recognized the importance of university sports teaching sustainable innovation ability, build up the Heilongjiang province university sports teaching sustainable innovation ability of evaluation index system, using the AHP to confirm the evaluation index system of the weight of each index, using fuzzy evaluation to evaluate he Heilongjiang province university sports teaching sustainable innovation ability, provide a scientific method and new ideas to measure the Heilongjiang province university sports teaching sustainable innovation ability.
\end{abstract}

Keywords: sports teaching in university, the sustainable innovation capability, key indicato rs identification; AHP - Fuzzy comprehensive

\section{The Introduction}

Sports teaching is an important part of national education career, is the important means of school education and the important content of school curriculum system, it is shouldering the national construction and development of education undertakings, promote all-round development of college education, and enhance the comprehensive strength of colleges and universities in China. As I have the development of higher education and the deepening of the reform and opening up, the importance of education in colleges and universities sports teaching in colleges and universities is increasingly important, has become one of the important object of reform of higher education in-depth reform. The stand or fall of the PE teaching reform finally to the deep reform in higher education has a great impact. Is the foundation of the national sports in colleges and universities sports teaching, is the development of higher student physique, physical quality improve, pluralistic interest cultivation, bears hardships and stands hard work spirit shape important guarantee, is enter higher professional talents for the national sports one of the important ways of [1].Colleges and universities sports teaching ability of continuous innovation is the driving force for the comprehensive development of education in colleges and universities, at the same time, the continuous innovation of university physical education ability strong or weak relationship to the effect of deepening reform in institutions of higher learning education. Therefore, colleges and universities sports teaching traditional alone, single, rigid teaching method and teaching form is difficult to adapt to the pace of the national education reform and the international sports development direction. Therefore, colleges and universities sports teaching in the process of deepening education reform increasingly by the institutions of higher learning and national attention and pay special attention to, especially focus on university sports teaching continuous innovation ability, it is only through constant innovation and development of new education mode, the ways of teaching and the establishment of teaching environment, in order 
to improve the students interest and study atmosphere, to develop a high comprehensive quality to the nation's XuQiuXing talent. Then evaluate the ability of continuous innovation in colleges and universities sports teaching, not only conducive to the physical education teaching in colleges and universities estimates made objective continuous innovation ability, and good for finding specific solutions to college sports teaching innovation and continuous development of innovation bottleneck, for the physical education teaching in colleges and universities continue to provide scientific innovation ability evaluation methods, enhance the capacity of continuous innovation of physical education in colleges and universities, institutions of higher learning in our country can keep the input to the nation as a whole with high quality and reliable high-quality talents with professional skills, so as to set up the country in the international sports and education in the cause of higher image, and make the country education enterprise, the development of undertakings of physical culture and sports to achieve better and faster.

\section{Literature Review}

From existing a large number of literatures can be found that the university sports teaching literature is very abundant, but the university sports teaching literature few continuous innovation ability. Existing in the college physical education teaching research mainly focus on the construction of colleges and universities sports teaching evaluation system, research; After the system build feasibility study; The study of individual sport teaching innovation; Research on university sports teaching curriculum structure; The study of college PE teaching environment; University sports teaching model research, however, the science of mathematics method of continuous innovation in colleges and universities sports teaching research is little. However, continuous innovation ability of physical education in colleges and universities sports education development of colleges and universities and the comprehensive development of colleges and universities plays a vital role, only to find the university sports teaching innovation should focus on from which aspects of the ability to enhance and improve, to promote the development of colleges and universities sports teaching faster, therefore, this article in Chen (2009) [2], Wu jiang (2012) [3], Li lei (2013) [4], Xiaoying Qu(2014) [5] and other scholars based on the study of physical education teaching in colleges and universities, from the Angle of continuous innovation ability, study of colleges and universities sports teaching evaluation, so as to enrich college sports teaching research, continuous innovation ability evaluation of PE of universities and colleges provide scientific methods and new ideas.

\section{Continuous Innovation Ability Evaluation Index System of Primary PE of Universities and Colleges to Build}

Continuous innovation in colleges and universities sports teaching ability is influenced by many aspects, the first will be influenced by outside factors, including the related national policy, strategy, collaborators, and national and international trend and direction of the development of the sports, education, etc.; Second are influenced by the colleges and universities internal factors, including internal self innovation resources in colleges and universities, innovation knowledge, innovation ability, innovation culture and innovation awareness, teachers' innovation ability and the innovation of the university itself, factors such as decision-making and development strategy, these factors will directly determine the effect of continuous innovation in colleges and universities sports teaching [6].Under the condition of certain university sports education for innovative ability of university sports teaching strategies, colleges and universities sports teaching innovation environment, teachers' innovation ability, college sports students comprehensive ability and so on four aspects. Strategic layout capability such as universities of physical education in colleges and universities of college development strategy adjustment ability, innovation ability of colleges and universities choose partner schools, colleges and universities leadership's ability to foresee national sports development direction, corporate support of college sports, and other 
factors directly affect the continuous innovation of university physical education direction selection and determination of the target; Colleges and universities sports teaching innovation environment shape the ability of the comprehensive quality of physical education teachers, sports facilities, sports training standards, the popularity of the information-based teaching factors such as height, smooth implementation is continuous innovation in colleges and universities sports teaching strategy to carry out the key factors [7]; Teachers' ability to innovate in the traditional and new type of sports ability, personality education ability, teachers' skills and knowledge to reflect degree of coherence, modernization of intuitive teaching ability is fast realization of teaching in colleges and universities sports teaching strategy target, enhance the ability of continuous innovation in colleges and universities sports teaching the vital factors; College students comprehensive ability of sports technical quality control, technical skills, ability to apply, the condition of sports knowledge, psychological compressive ability, are the final measure of the ability of continuous innovation in colleges and universities sports teaching, universities take the university sports teaching is an important index for the strategic adjustment of continuous innovation and the reference. Follow a comprehensive, scientific, operational principle and quantifiable, in reference on the basis of existing research results, from the university sports teaching strategies, colleges and universities sports teaching innovation environment, teachers' innovation ability, college sports students comprehensive abilities in four dimensions to build the ability of continuous innovation in colleges and universities sports teaching primary evaluation index system, including four secondary index and 34 three-level index, specific content as shown in table 1:

Table 1. The Ability of Continuous Innovation in Colleges and Universities Sports Teaching Primary Evaluation Index System

\begin{tabular}{|c|c|c|}
\hline Goal level & Criterion level & Index level \\
\hline $\begin{array}{l}\text { the ability of } \\
\text { continuous } \\
\text { innovation in } \\
\text { colleges and } \\
\text { universities } \\
\text { sports teaching } \\
\text { primary } \\
\text { evaluation } \\
\text { index system }\end{array}$ & $\begin{array}{l}\text { colleges and } \\
\text { universities } \\
\text { sports teaching } \\
\text { innovation } \\
\text { environment }\end{array}$ & $\begin{array}{l}\text { (1) the adjustment ability of university leadership on the } \\
\text { development strategy of colleges and Universities }\left(a_{11}\right) \\
\text { (2) the innovation ability to select the universities partner } \\
\text { and in colleges and universities }\left(a_{12}\right) \\
\text { (3) the ability to foresee the leadership of the state sports } \\
\text { development direction }\left(a_{13}\right) \\
\text { (4) enterprise support for physical education in colleges } \\
\text { and universities }\left(a_{14}\right) \\
\text { (5) the leadership recognition ability on the future of the } \\
\text { international trend }\left(a_{15}\right) \\
\text { (6) the ability to foresee environmental change }\left(a_{16}\right) \\
\text { (7) government policy on the physical support }\left(a_{17}\right) \\
\text { (8) college sports training plan set reasonable }\left(a_{18}\right) \\
\text { (9) the leadership recognition ability of technical change } \\
\left.\text { ( } a_{19}\right) \\
\text { (1) the comprehensive quality of sports teachers }\left(a_{21}\right) \\
\text { (2) sports facilities improved }\left(a_{22}\right) \\
\text { (3) physical training standard }\left(a_{23}\right) \\
\text { (4) the popularity of information technology teaching }\left(a_{24}\right) \\
\text { (5) The popularity of multimedia sports teaching }\left(a_{25}\right) \\
\text { (6) the relationship between colleges and universities } \\
\text { cooperation }\left(a_{26}\right) \\
\text { (7) teachers exchange learning opportunities }\left(a_{27}\right)\end{array}$ \\
\hline
\end{tabular}




$\begin{array}{cl}\text { teachers' } & \text { degree }\left(a_{33}\right) \\ \text { innovation } & \text { (4) the teaching goal setting reasonable }\left(a_{34}\right) \\ \text { ability } & \text { (5) the ability to visually modernization teaching }\left(a_{35}\right) \\ & \text { (6) the teaching content of moderate difficulty }\left(a_{36}\right) \\ & \text { (7) the reasonable curriculum structure }\left(a_{37}\right) \\ & \text { (8) the theory and practice combine ability }\left(a_{38}\right) \\ & \text { (1) master the technology quality }\left(a_{41}\right) \\ \text { college sports } & \text { (2) technical application ability }\left(a_{42}\right) \\ \text { students } & \text { (3) the cognitive status of sports knowledge }\left(a_{43}\right) \\ \text { comprehensiv } & \text { (4) psychological resilience }\left(a_{44}\right) \\ \text { e abilities } & \text { (5) emotion regulation ability }\left(a_{45}\right) \\ & \text { (6) technical skills }\left(a_{46}\right) \\ & \text { (7) physical health status }\left(a_{47}\right)\end{array}$

\section{Based on Group Decision Characteristic Root Method in Colleges and Universities Sports Teaching Continuous Innovation Ability Evaluation Index to Identify Key}

Because many factors affect the ability of the continuous innovation in colleges and universities sports teaching, involves the content is very broad, so evaluation index identification is a key link in the process of continuous innovation capability evaluation of PE of universities and colleges. Academia to the colleges and universities sports teaching continuous innovation ability evaluation indexes of the few, the existing research using fuzzy analytic hierarchy process (AHP) and clustering methods such as comprehensive analysis of relevant indicators, it is concluded that the evaluation results [8].This article USES the group decision-making characteristic root method (GEM) to solve this problem, compared with the analytic hierarchy process (AHP), group decision-making characteristic root method (GEM) can not only overcome the inconsistency of judgment matrix, and without thinking about the weights of experts, also relatively simple calculation. Group decision-making characteristic root method (GEM) group (G) for multiple selves targets for new characteristic root method evaluation decision. Using this method only needs expert on each index score, then the score matrix transpose square of matrix F.F the maximum characteristic root corresponds to the characteristics of small amount is the optimal decision conclusion.

\subsection{The Theoretical Model of Group Decision-making Characteristic Root Method}

(1) The definition of ideal expert

$\mathrm{M}$ expert group decision system $\mathrm{G}$ is insisted of $S_{1}, S_{2}, S_{3}, \ldots, S_{m}$, evaluation target is $B_{1}, B_{2}, B_{3} \ldots, B_{n}$, the $\mathrm{i}$ expert makes scores of the $\mathrm{i}$ evaluation target $\mathrm{B}$ is $x_{i j} \in[I, J](i=1,2,3 \ldots m, j=1,2,3 \ldots n)$, the more bigger $x_{i j}$ score, the more important $B_{j}$. $S_{i}$ and G consist of $x_{i}$ and $m \times n$ 。 


$$
x_{i}=\left(x_{i 1}, x_{i 2}, x_{i 3}, \ldots, x_{i n}\right)^{T} \in E^{n},
$$

$$
x=\left(x_{i j}\right)_{m \times n}=\left[\begin{array}{cccc}
x_{11} & x_{12} & \ldots & x_{1 n} \\
x_{21} & x_{22} & \ldots & x_{2 n} \\
\ldots & \ldots & \ldots & \ldots \\
x_{m 1} & x_{m 2} & \ldots & x_{m n}
\end{array}\right]
$$

They are the conclusion of experts in a decision, each member group of experts on the evaluation of the value of the object. Score vector of ideal expert is $x_{*}=\left(x_{*_{1}}, x_{*_{2}}, \ldots, x_{*_{n}}\right)^{T} \in E^{n}$, the ideal experts have highly consistency in the evaluation of the evaluation target and group G, that is, $S_{*}$ and G have the identical results. The ideal (optimal) definition for groups in the related literature is the expert score vector and group score vector angle and minimum expert [9].

Therefore, $x_{*}$ is the positive characteristic vector when $f=\sum_{i=1}^{m}\left(b^{T} x_{i}\right)^{2}$ solves a maximum value, formula $\forall b=\left(b_{1}, b_{2}, b_{3}, \ldots, b_{n}\right) \in E^{n}$, suppose $\|b\|=1$, that is $\max _{\|b\|=1} \sum_{i=1}^{m}\left(b^{T} x_{i}\right)^{2}=\sum_{i=1}^{m}\left(x_{*}^{T} x_{*}\right)^{2}$, of that $x_{*}$ is the total score.

(2) The evaluation index weight solution theorem

Theorem 1: $b \forall \in E^{n}, \max _{b \in E^{n}} \sum_{i=1}^{m}\left(b^{T} x_{i}\right)^{2}=\rho_{\max }$, of that, $\rho_{\max }$ is the biggest single root of $F=X^{T} X ; x_{*}$ is the positive characteristic vector $\rho_{\max }$ to $X^{T} X$, and $\left\|x_{*}\right\|=1$.

Theorem 2: Suppose A is $m \times n$ matrix, B is $n \times m$ matrix, so AB and BA have the same (including multiplicities) non zero eigenvalue.

Theorem 3: ${ }^{a}{ }_{0}$ is the eigenvectors to $X^{T} X$, and $\left\|a_{0}\right\|=1$, so there is $X^{T} a_{0}=K X_{*}$, that is, ${ }^{a}$ is the weight vector of $m$ experts.

(3)The processing of single and double root

If the maximum characteristic root is a single, the corresponding eigenvectors has a unique optimal solution; If value their biggest characteristic root root, and work out its characteristic vector space, then the characteristic vector space corresponding to the evaluation index that is equally important, other is evaluating object with the second largest eigenvectors corresponding to characteristic root ranking or removed in the score matrix has tied for ranking score values of the evaluation, to reconstruct a matrix, with the second evaluation.

\subsection{Continuous Innovation Ability Evaluation Index to Identify Key University Physical Education}

In this paper, by the method of group decision characteristic root, continuous innovation in colleges and universities sports teaching ability to identify the importance of the evaluation in dex, find out the key indicators. By experts from universities and research institutes, governm ent agencies, the questionnaire survey in 5 grade evaluation method are very reasonable and $u$ nreasonable, reasonable, fair and reasonable, and its corresponding points, respectively is 1,2 , $3,4,5$ points. Teachers' innovation capability index, for example given by the expert assess ment, as shown in Table 2: 
Table 2. The Expert Score Table of Teachers' Innovation Capability Index

\begin{tabular}{lllllllll}
\hline & $a_{31}$ & $a_{32}$ & $a_{33}$ & $a_{34}$ & $a_{35}$ & $a_{36}$ & $a_{37}$ & $a_{38}$ \\
\hline $\mathrm{S}_{1}$ & 5 & 4 & 3 & 5 & 5 & 2 & 2 & 1 \\
$\mathrm{~S}_{2}$ & 4 & 5 & 2 & 4 & 3 & 1 & 2 & 3 \\
$\mathrm{~S}_{3}$ & 5 & 3 & 3 & 5 & 4 & 2 & 1 & 2 \\
$\mathrm{~S}_{4}$ & 5 & 4 & 2 & 3 & 5 & 1 & 2 & 1 \\
$\mathrm{~S}_{5}$ & 4 & 5 & 1 & 4 & 3 & 3 & 3 & 4 \\
$\mathrm{~S}_{6}$ & 4 & 4 & 3 & 5 & 5 & 2 & 1 & 2 \\
$\mathrm{~S}_{7}$ & 5 & 3 & 2 & 4 & 4 & 1 & 2 & 1 \\
$\mathrm{~S}_{8}$ & 3 & 5 & 4 & 5 & 4 & 2 & 1 & 2 \\
$\mathrm{~S}_{9}$ & 5 & 4 & 3 & 3 & 5 & 3 & 2 & 3 \\
$\mathrm{~S}_{10}$ & 4 & 5 & 2 & 4 & 3 & 2 & 1 & 1 \\
$\mathrm{~S}_{11}$ & 3 & 5 & 1 & 5 & 4 & 1 & 2 & 2 \\
$\mathrm{~S}_{12}$ & 4 & 4 & 2 & 5 & 3 & 3 & 1 & 4 \\
$\mathrm{~S}_{13}$ & 5 & 3 & 3 & 4 & 5 & 2 & 1 & 3 \\
$\mathrm{~S}_{14}$ & 5 & 4 & 1 & 3 & 5 & 1 & 2 & 1 \\
$\mathrm{~S}_{15}$ & 4 & 5 & 2 & 4 & 5 & 2 & 1 & 2 \\
\hline
\end{tabular}

Use MATLAB software and make the expert score matrix transpose, the result is:

$$
F=x^{T} x=\left[\begin{array}{cccccccc}
289 & 267 & 148 & 269 & 277 & 121 & 105 & 136 \\
267 & 273 & 140 & 265 & 261 & 118 & 102 & 136 \\
148 & 140 & 88 & 146 & 146 & 66 & 55 & 72 \\
269 & 265 & 146 & 273 & 262 & 119 & 98 & 136 \\
277 & 261 & 146 & 262 & 275 & 116 & 100 & 129 \\
121 & 118 & 66 & 119 & 116 & 60 & 44 & 67 \\
105 & 102 & 50 & 98 & 100 & 44 & 44 & 52 \\
136 & 136 & 72 & 136 & 129 & 67 & 52 & 84
\end{array}\right]
$$

According to the calculation, the maximum eigenvalue is single, and $\rho_{\max }=1315.8235294$, of that, The corresponding eigenvector for:

$$
B^{T}=(0.4622,0.4473,0.2448,0.4491,0.4498,0.2017,0.1699,0.2296)
$$

For each feature vector processing units, get that:

$$
B^{T}=(0.1741,0.1685,0.0922,0.1691,0.1695,0.0759,0.0640,0.0865)
$$

The vector B is the relative importance of the factors between the ranking.

Through the elements in order of importance analysis, identification and selection of key indicators, through the analysis to eliminate the importance evaluation index of less than 0.1000. The relative importance of the index $a_{31} a_{32} a_{34} a_{35}$ is $0.1741,0.01685,0.1691,0.1695$, all are more than 0.1000 , so those index are retained; The relative importance of the index $a_{33}$ $a_{36} a_{37} a_{38}$ is $0.0922,0.0759,0.0640,0.0865$, all are less than 0.1000 , so those index are eliminated. Finally, through screening, the retained index are $\left(a_{31} a_{32} a_{34} a_{35}\right)$.

Use MATLAB software, similarly, screening out the other important indicators in criterion level. The screened index are shown in Table 3. 
Table 3. The Evaluation Index of College Sports Teaching Continuing Innovation Ability

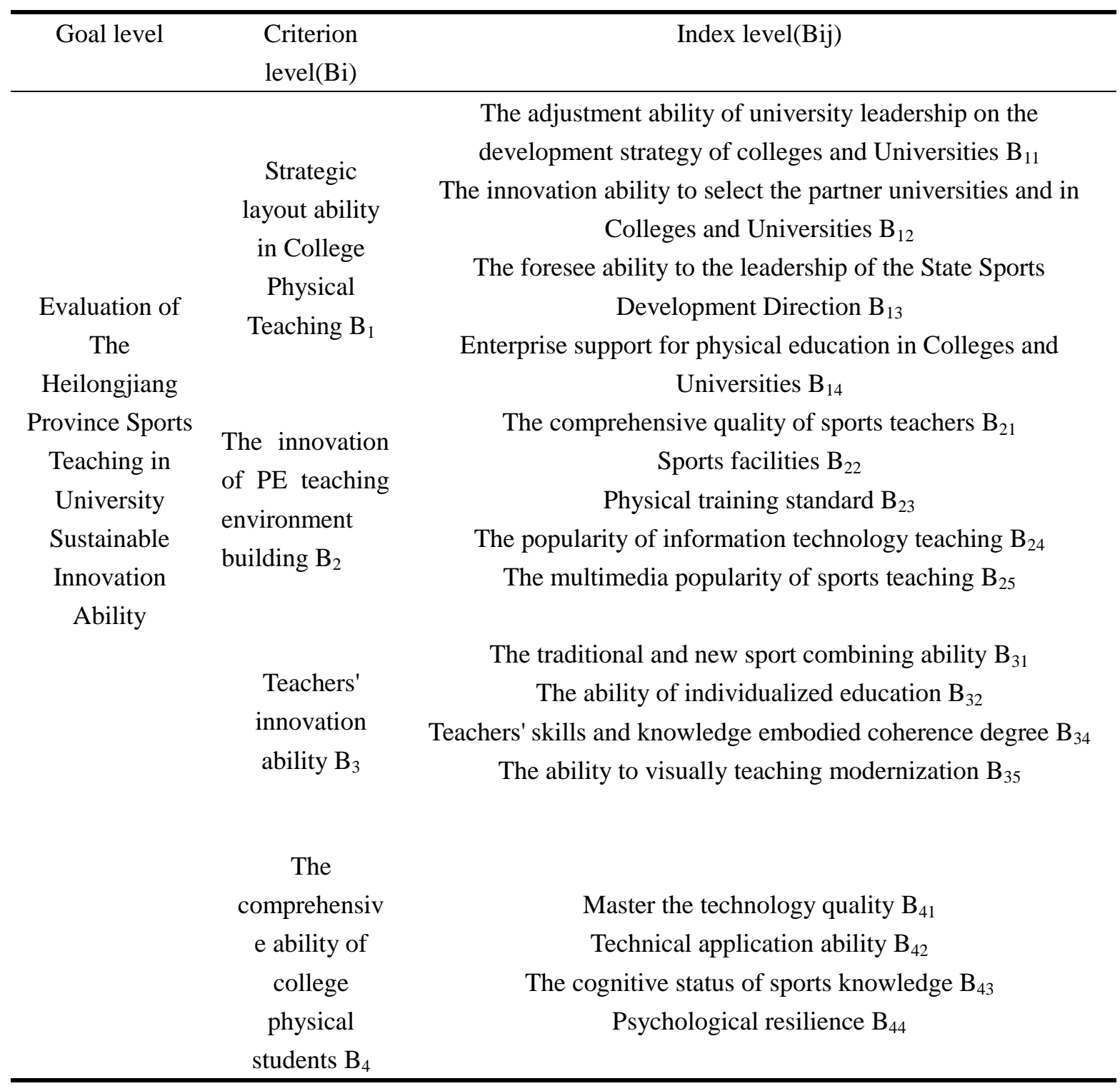

\section{Continuous Innovation Capability in Heilongjiang Province University Sports Teaching the AHP and Fuzzy Comprehensive Evaluation}

\subsection{The AHP Index Weight Calculation}

\subsubsection{Hierarchy Model was Constructed}

Using analytic hierarchy process (ahp), the first should be based on the main factors affecti ng college PE teaching continuous innovation ability to build hierarchical structure. In buildin $\mathrm{g}$ this structure, the key is to distinguish the relationship between various factors and which fa ctors are at the next higher level, what its subordinate factors. According to Table 3 determine $\mathrm{s}$ the main influence factor and subordinate factors, finally determine the hierarchical structur e model as shown in Table 3.

\subsubsection{Structure Determination of Judgment Matrix and its Weights}

After using hierarchical analysis, according to the upper and lower levels of subordinate 
relations, construct the judgment matrix. Namely above a level one factor as the criterion, it to the next level factors have dominated relationship, through pairwise comparison of the relative importance of the next level, and give a certain score, commonly used Satty scale method proposed by professor [10].To the civil-military integration enterprise sustainable innovation ability evaluation index hierarchy, such as Table 4.According to the result of expert advice to construct judgment matrix calculation results are shown in Table $5 \sim 8$ : criterion layer four indicators of the university sports teaching strategy layout, colleges and universities sports teaching innovation environment, teachers' innovation ability, college sports students comprehensive ability to the target layer of the value of the individual elements of judgement matrix and final calculation of the index of the four results are shown in Table 4

Table 4. The Heilongjiang Province University Sports Teaching Ability of Persistent Innovation System of Judgment Matrix and Weight

\begin{tabular}{llllll}
\hline & $\mathrm{B}_{1}$ & $\mathrm{~B}_{2}$ & $\mathrm{~B}_{3}$ & $\mathrm{~B}_{4}$ & Index weight \\
\hline $\mathrm{B}_{1}$ & 1 & 2 & 2 & 2 & 0.3387 \\
$\mathrm{~B}_{2}$ & $1 / 2$ & 1 & 2 & $1 / 3$ & 0.1855 \\
$\mathrm{~B}_{3}$ & $1 / 2$ & $1 / 2$ & 1 & 3 & 0.2419 \\
$\mathrm{~B}_{4}$ & $1 / 2$ & 3 & $1 / 3$ & 1 & 0.2339 \\
\hline
\end{tabular}

The judgement matrix from index level to criterion level:

Table 5. The Relative Important Degree between Comparison Judgment Matrix of PE Teaching in Colleges and Universities Strategic Layout

\begin{tabular}{llllll}
\hline & $\mathrm{B}_{11}$ & $\mathrm{~B}_{12}$ & $\mathrm{~B}_{13}$ & $\mathrm{~B}_{14}$ & Index weight \\
\hline $\mathrm{B}_{11}$ & 1 & $1 / 2$ & 1 & 2 & 0.2500 \\
$\mathrm{~B}_{12}$ & 2 & 1 & 1 & $1 / 2$ & 0.2500 \\
$\mathrm{~B}_{13}$ & 1 & 1 & 1 & 2 & 0.2778 \\
$\mathrm{~B}_{14}$ & $1 / 2$ & 2 & $1 / 2$ & 1 & 0.2222 \\
\hline
\end{tabular}

Table 6. The Relative Important Degree between Comparison Judgment Matrix of the Innovation of PE Teaching Environment Building

\begin{tabular}{lllllll}
\hline & $\mathrm{B}_{21}$ & $\mathrm{~B}_{22}$ & $\mathrm{~B}_{23}$ & $\mathrm{~B}_{24}$ & $\mathrm{~B}_{25}$ & Index weight \\
\hline $\mathrm{B}_{21}$ & 1 & $1 / 2$ & $1 / 2$ & 1 & $1 / 2$ & 0.1250 \\
$\mathrm{~B}_{22}$ & 2 & 1 & 1 & 2 & 1 & 0.2500 \\
$\mathrm{~B}_{23}$ & 2 & 1 & 1 & 2 & 1 & 0.2500 \\
$\mathrm{~B}_{24}$ & 1 & $1 / 2$ & $1 / 2$ & 1 & $1 / 2$ & 0.1250 \\
$\mathrm{~B}_{25}$ & 2 & 1 & 1 & 2 & 1 & 0.2500 \\
\hline
\end{tabular}


Table 7. The Relative Important Degree between Comparison Judgment Matrix of Teachers' Innovation Ability

\begin{tabular}{llllll}
\hline & $\mathrm{B}_{31}$ & $\mathrm{~B}_{32}$ & $\mathrm{~B}_{33}$ & $\mathrm{~B}_{34}$ & Index weight \\
\hline $\mathrm{B}_{31}$ & 1 & $1 / 2$ & $1 / 3$ & $1 / 2$ & 0.1206 \\
$\mathrm{~B}_{32}$ & 2 & 1 & 1 & $1 / 2$ & 0.2328 \\
$\mathrm{~B}_{33}$ & 3 & 1 & 1 & $1 / 2$ & 0.2845 \\
$\mathrm{~B}_{34}$ & 2 & 2 & 2 & 1 & 0.3621 \\
\hline
\end{tabular}

Table 8. The Relative Important Degree between Comparison Judgment Matrix of the Comprehensive Ability of College Physical Students

\begin{tabular}{llllll}
\hline & $\mathrm{B}_{41}$ & $\mathrm{~B}_{42}$ & $\mathrm{~B}_{43}$ & $\mathrm{~B}_{44}$ & Index weight \\
\hline $\mathrm{B}_{41}$ & 1 & $1 / 2$ & $1 / 3$ & 1 & 0.1465 \\
$\mathrm{~B}_{42}$ & 2 & 1 & $1 / 2$ & 2 & 0.2845 \\
$\mathrm{~B}_{43}$ & 3 & 2 & 1 & 2 & 0.4138 \\
$\mathrm{~B}_{44}$ & 1 & $1 / 2$ & $1 / 2$ & 1 & 0.1552 \\
\hline
\end{tabular}

Through the consistency checking, the consistency ratio indexes were all less than 0.1 , namely all through the consistency test.

\subsection{Fuzzy Comprehensive Evaluation}

(1) Determine the evaluation index set $A=\left\{B_{1}, B_{2}, B_{3}, B_{4}\right\}$, Represent the college sports teaching strategic layout, universities sports teaching innovation environment, innovation ability, students' comprehensive ability. Determination evaluation index subset $\mathrm{B}_{\mathrm{i}}=\left\{\mathrm{B}_{\mathrm{ij}}\right\}(\mathrm{i}=1,2,3,4 ; \mathrm{j}=1,2,3,4,5)$.

(2) Determine the remark grade and the corresponding standard, Determine comments $\mathrm{V}=\left\{\mathrm{V}_{1}, \mathrm{~V}_{2}, \mathrm{~V}_{3}, \mathrm{~V}_{4}, \mathrm{~V}_{5}\right\}=\{$ more poor, poor, common, good, very good $\}$, The corresponding evaluation vector $\mathrm{V}=\{1,2,3,4,5\}$.

(3) Determine the weight vector of different levels index. The table 6- table 10 to determine the index weight vector:

One level index: $W_{4}=\{0.3387,0.1855,0.2419,0.2339\}$

Two level index: $\mathrm{W}_{5}=\{0.2500,0.2500,0.2778,0.2222\}$

$$
\begin{aligned}
& \mathrm{W}_{6}=\{0.1250,0.2500,0.2500,0.1250,0.2500\} \\
& \mathrm{W}_{7}=\{0.1206,0.2328,0.2845,0.3621\} \\
& \mathrm{W}_{8}=\{0.1465,0.2845,0.4138,0.1552\}
\end{aligned}
$$

(4) Invite 10 experts to evaluate the continuing education of College Physical Education in Heilongjiang province innovation ability, according to experts' understanding of sustainable innovation ability in the teaching of college sports in Heilongjiang Province, by each expert alone of index layer of each indicator for rank. Because of the fuzzy index, integrate each expert on the number of indexes, the index belong to a remark grade of membership. 


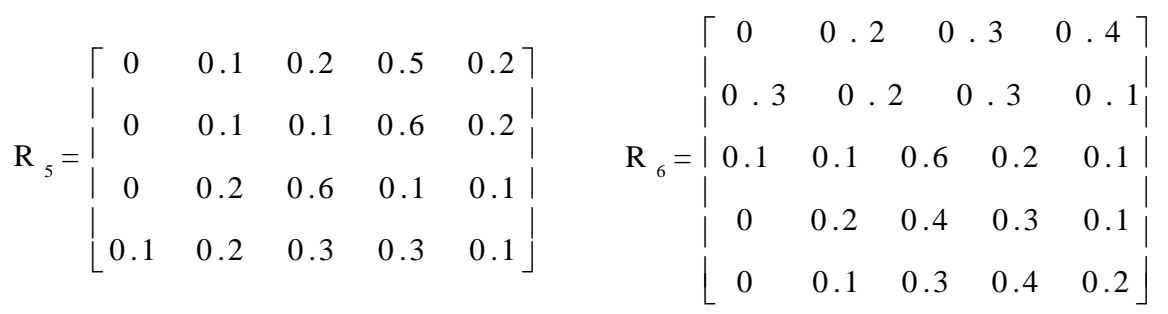

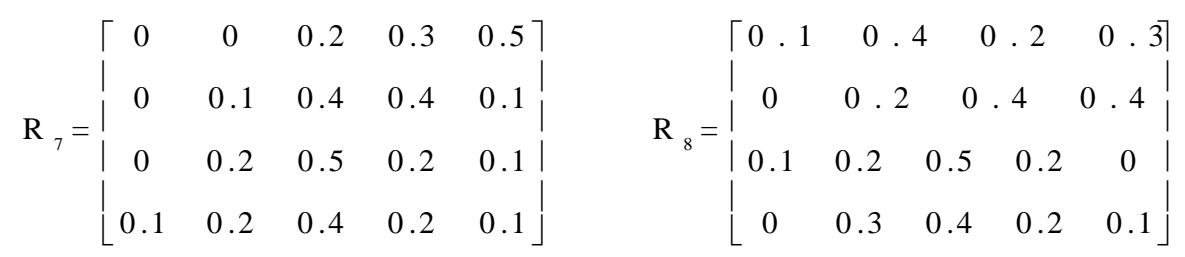

(5) The single factor evaluation

$$
\begin{aligned}
& \mathrm{D}_{1}=\mathrm{W}_{5} \bullet \mathrm{R}_{5}=(0.0222,0.1500,0.3083,0.3694,0.1500) \\
& \mathrm{D}_{2}=\mathrm{W}_{6} \bullet \mathrm{R}_{6}=(0.1000,0.1500,0.3875,0.2625,0.0750) \\
& \mathrm{D}_{3}=\mathrm{W}_{7} \bullet \mathrm{R}_{7}=(0.0362,0.1526,0.4043,0.2586,0.1483) \\
& \mathrm{D}_{4}=\mathrm{W}_{8} \bullet \mathrm{R}_{8}=(0.0560,0.2448,0.4121,0.2716,0.0155)
\end{aligned}
$$

Get:

$\mathrm{D}=\left\{\begin{array}{l}D_{1} \\ D_{2} \\ D_{3} \\ D_{4}\end{array}\right]=\left[\begin{array}{lllll}0.0222 & 0.1500 & 0.3083 & 0.3694 & 0.1500 \\ 0.1000 & 0.1500 & 0.3875 & 0.2625 & 0.0750 \\ 0.0362 & 0.1526 & 0.4043 & 0.2586 & 0.1483 \\ 0.0560 & 0.2448 & 0.4121 & 0.2716 & 0.0155\end{array}\right]$

$\mathrm{B}_{1}=\mathrm{D}_{1} \bullet C^{T}=3.4747$

$\mathrm{B}_{2}=\mathrm{D}_{2} \cdot C^{T}=2.9875$

$\mathrm{B}_{3}=\mathrm{D}_{3} \cdot C^{T}=3.3302$

$\mathrm{B}_{4}=\mathrm{D}_{4} \cdot C^{T}=2.9458$

(6) The comprehensive evaluation index

$$
\begin{aligned}
& \mathrm{A}=\mathrm{W}_{4} \bullet D=(0.0481,0.1728,0.3727,0.2999,0.1065) \\
& \mathrm{B}=\mathrm{A} \bullet C^{T}=3.2439 \\
& \lambda_{\text {max }}=\frac{1}{m} \sum_{i=1}^{m} \frac{(A W)_{i}}{w_{i}}
\end{aligned}
$$


$C R=\frac{C I}{R I}=\frac{\left(\lambda_{\max }-n\right) /(n-1)}{R I}$

$C R \leq 0.1$ judgment matrix has the satisfactory consistency.

\section{The Conclusion}

This paper, by means of the GEM, identified the ability of continuous innovation in Colleg es and universities sports teaching system is an important evaluation index, USES AHP metho $\mathrm{d}$ to calculate the index weights of indicators to criterion layer, as well as the criterion to the ta rget layer of the weight of each index. On the basis of AHP method to calculate the weight, th rough fuzzy comprehensive evaluation in Heilongjiang province university sports teaching co ntinuous innovation ability scored 3.2439, show that Heilongjiang province colleges and univ ersities sports teaching continuous innovation ability as a whole is still in the average level. C ontinuous innovation ability index system of PE of universities and colleges in Heilongjiang $\mathrm{p}$ rovince rule layer evaluation results showed that the universities sports teaching strategy layo ut (3.4747) and the university sports teaching innovation environment capacity (2.9875) is str onger, teachers' innovation ability (3.3302) and college sports students comprehensive ability (2.9458) is relatively weak. So, continuous innovation in Heilongiiang province university sp orts teaching in the teachers' ability to innovate and college sports students need further streng then the comprehensive ability to improve.

\section{Acknowledgement}

The paper is sponsored by Heilongjiang province higher education scientific research "twelfth five-year" plan project (HGJXHC110378).

\section{References}

[1] H. Feng, "About the school sports teaching research", Beijing Sport University, 2012.

[2] F. Chen, "The study of common colleges and universities sports teaching evaluation system", Journal of reform and openness, vol.8, (2009).

[3] J. Wu and J. Song, "Ordinary university sports teaching evaluation system construction and operability", Journal of social scientists, vol. 10, (2012).

[4] L. Lei and H. Liu, "School sports teaching system construction and operational research", Contemporary sports science and technology, vol. 2, (2013).

[5] X. Qu, "Under the perspective of informational reform and innovation of college sports information service", Journal of Electronic Test, vol. 1, (2014).

[6] C. Liming, C. An, "College sports teachers' current comprehensive quality structure and cultivation methods", Journal of education and profession, vol. 3, (2013).

[7] W. Sen, "Explore the evaluation system of college PE teaching and learning", Journal of exam week, vol. 57, (2012).

[8] X. Shu, "The theory of modern sports teaching theory and teaching reform", Journal of Shanxi education, vol.9, (2006)

[9] "The high Wan China group decision-making characteristic root method", Journal of applied mathematics and mechanics, vol. 17, no. 11, (1997), pp. 1027-1031.

[10] "IARRATANO JG principle and programming", Expert management system, Beijing: mechanical industry press, (2000), pp. 217-220. 
International Journal of Multimedia and Ubiquitous Engineering

Vol. 10, No. 1 (2015) 